Теория корабля и строительная механика

DOI: http://www.dx.doi.org/10.24866/2227-6858/2020-3-4

УДК 629.124

\title{
В.М. Козин
}

КОЗИН ВИКТОР МИХАЙЛОВИЧ - д.Т.Н., профессор по кафедре кораблестроения, главный научный сотрудник Института машиноведения и металлургии ДВО РАН, SPIN: 1265-7970, ResearchersID: S-6053-2016, ScopusID: 8548383800, ORCID: https://orcid.org/0000-0002-2673-469X, e-mail: kozinvictor@rambler.ru Хабаровский фредеральный исследовательский центр ДВО РАН Комсомольск-на-Амуре, Россия

\section{Увеличение ледоразрушающей способности изгибно-гравитационных волн при их приближении к берегу}

Аннотация: Рассматривается возможность повышения эффективности резонансного метода разрушения ледяного покрова, т.е. путем возбуждения во льду резонансных изгибно-гравитационных волн амфибийными судами на воздушной подушке, при решении таких важных народнохозяйственных задач, как борьба с ледовыми осложнениями в виде заторов и зажоров на реках, текущих с юга на север; продление навигации на внутренних водных путях; раннее вскрытие ото льда водохранилищ на нижнем бьефе гидроэлектростанций с целью повышения их выработки электроэнергии и других задач за счет использования соответствующего маневрирования судов вблизи берега. Ввиду сложности процесса разрушения ледяного покрова из-за влияния на него близости берега в работе приведены только общие сведения по разрушению льда натурными судами на воздушной подушке в полевых условиях и результаты исследований, выполненных в опытовом бассейне на моделирующих ледяной покров упругих пленках. Показано, что использование такого маневра, как выход судна на берег во время выполнения ледокольных работ, может существенно повысить эффективность резонансного метода разрушения ледяного покрова, т.е. снизить энергозатраты на разрушение льда по сравнению с его реализацией в условиях бесконечного ледяного поля. Таким образом, было установлено, что в случаях, когда ледяной покров не удавалось разрушить при движении судов с резонансной скоростью (вес судна и давление в его воздушной подушке были недостаточными для разрушения льда данной толщины), то удавалось разрушить кромку льда при движении судна под углом к береговой линии с последующим выходом на берег. После чего, как показали результаты исследований, деформации ледяного покрова при последующем движении судов вдоль образовавшейся свободной кромки, а значит и изгибные напряжения во льду, существенно возрастали. В работе представлены результаты экспериментальных модельных исследований зависимости высоты изгибно-гравитационных волн, возбуждаемых в ледяном покрове движущейся нагрузкой, при выходе их на берег от угла наклона дна бассейна. Также приведены рекомендации по использованию угла наклона дна для повышения эффективности разрушения ледяного покрова (увеличения толщины разрушаемого льда) резонансным методом.

Ключевые слова: ледяной покров, изгибно-гравитационные волны, движущаяся нагрузка, суда на воздушной подушке, резонансный метод, наклон дна.

(C) Козин В.М., 2020

О статье: поступила: 24.03.2020; финансирование: работа выполнена в рамках государственного задания Института машиноведения и металлургии Хабаровского федерального исследовательского центра ДВО РАН № 075-01032-20-00. 


\section{Введение}

Решение таких ледотехнических проблем, как борьба с ледовыми осложнениями в виде заторов и зажоров на реках, текущих с юга на север; продление навигации на внутренних водных путях, раннее вскрытие ото льда водохранилищ на нижнем бьефе гидроэлектростанций с целью повышения их выработки электроэнергии, поведение и разрушение ледяного покрова от действия динамических нагрузок имеет важное народнохозяйственное значение. Об этом свидетельствует значительное количество публикаций, первые из которых появились еще в конце XIX века. Относительно подробный обзор работ по распространению в ледяном покрове изгибно-гравитационных волн (ИГВ), возбуждаемых динамическими нагрузками, приведен в [5]. В настоящей статье указаны лишь работы примерно за последний десяток лет и наиболее близкие, на наш взгляд, к рассматриваемой задаче. Так, в $[3,4]$ К.Н. Завьялова, К.А. Шишмарев и Т.И. Хабахпашева рассмотрели задачи по определению параметров колебаний битого льда в канале от движения по нему внешней нагрузки. Рассмотрена модельная задача с учетом вязкости льда, при этом битый лед моделировался тонкой упругой пластиной, а внешняя нагрузка - локализованным давлением, движущимся по поверхности льда с постоянной скоростью. За основу математической модели использовались дифференциальное уравнение колебаний битого льда и уравнение Лапласа для потенциала скорости движения жидкости подо льдом. И.О. Богульский в [1] рассмотрел задачу моделирования контакта толстого упругого слоя с вертикальной стенкой. Временную зависимость реакции вязкоупругой плавающей пластины от воздействия на нее импульсной движущейся нагрузки изучали Ван К., Р. Хоскинг и Ф. Милинаццо [17]. Ли Лян и К.Н. Шхинек в [7] исследовали предельную несущую способность ледяных балок. Особенности распространения волн, возбуждаемых вдоль канала с ледяным покровом, рассмотрены в работе А. Коробкина, Т. Хабахпашевой и А. Папина [16].

Поведению полубесконечного ледяного покрова при равномерном движении нагрузки, а также колебаниям ледяной пластины с трещиной при воздействии периодической нагрузки посвящены статьи Л.А.Ткачевой $[14,15]$. Плоская задача о воздействии нескольких ударных импульсов на вязкоупругую пластину, плавающую на поверхности жидкости, решена А.В. Погореловой в [9]. Статья Л.А.Ткачевой [13] посвящена плоской задаче о влиянии периодической внешней нагрузки на колебания полубесконечной упругой пластины. Задачи о дифракции поверхностных волн на плавающей упругой пластине и ее нестационарном поведении под действием внешней нагрузки на мелководье исследовались в работах И.В. Стуровой $[11,12]$. Волнам в море с плавающим ледяным покровом посвящена монография А.Е. Букатова [2]. А.А. Коробкин и Т.И. Хабахпашева в [6] рассмотрели варианты построения точных решений в задаче о плавающей пластине. Исследованиям затухания поверхностных гравитационных волн в прикромочной зоне дрейфующего льда посвящена работа А.В. Марченко и М.М. Чумакова [8]. В [10] рассмотрены различные задачи распространения поверхностных волн в ледовых условиях.

Проведенный анализ указанных выше и ранее выполненных нами работ [5] показал отсутствие исследований по рассматриваемой в настоящей статье задаче, т.е. повышению эффективности резонансного метода разрушения ледяного покрова (РМРЛ). Сущность этого метода изложена также в [5]. Ввиду сложности процесса разрушения ледяного покрова в таких условиях в [5] приведены только общие сведения по разрушению натурными судами на воздушной подушке (СВП) в полевых условиях и результаты исследований, выполненных в опытовом бассейне на моделирующих ледяной покров упругих пленках. Как показали наблюдения и предварительно выполненные эксперименты, с использованием такого маневра, как выход судна на берег во время выполнения ледокольных работ, можно существенно повысить эффективность РМРЛ, т.е. снизить энергозатраты на разрушение льда по сравнению с его реализацией в условиях бесконечного ледяного поля. 
Цель предлагаемой статьи - дать количественное определение увеличение высоты, т.е. ледоразрушающей способности возбуждаемых изгибно-гравитационных волн движущейся нагрузкой при ее приближении к берегу и последующим выходом на него.

\section{Экспериментальные подтверждения увеличения} ледоразрушающей способности ИГВ при их приближении к берегу

РМРЛ может осуществляться любым транспортным средством, обладающим способностью перемещаться по ледяному покрову с достаточной скоростью и возбуждающим ИГВ необходимой для разрушения льда амплитудой (изгибных напряжений), т.е. достаточными массово-габаритными характеристиками [5]. С этой точки зрения для эффективного использования и обеспечения безопасности эксплуатации при реализации РМРЛ транспортными средствами наиболее пригодны амфибийные СВП, ледоразрушающие качества которых исследовались в натурных условиях [5]. При этом во время проведения испытаний СВП «Скат» и «Гапард» на реке Амур (1984-1987 гг.) было обнаружено, что в случаях, когда ледяной покров не удавалось разрушить при движении судов с резонансной скоростью (вес судна и давление в его воздушной подушке были недостаточными для разрушения льда данной толщины), то кромку льда удавалось разрушить при движении судна под углом к береговой линии с последующим выходом на берег. Ее наличие обеспечивало существенное увеличение ледоразраушающей способности СВП. Так, толщина льда, разрушаемого СВП «Скат» (массой 22 т) при его движении вдали от берега не превышала 22 см, а при приближении судна к береговой линии возросла до 27 см. При разрушении ледяного покрова СВП «Гепард» (массой 6 т) в аналогичных условиях толщина разрушаемого льда возросла от 6 до $8 \mathrm{~cm}[5]$.

Очевидно, что это связано с трансформацией параметров ИГВ при их выходе на мелководье с наклонным дном водоема (в этих условиях происходит уменьшение длины с одновременном увеличением высоты ИГВ, т.е. увеличение изгибных напряжений во льду) и с их взаимодействием с отражёнными от берега волнами, т.е. за счет создания своеобразного гидроудара при их интерференции. После этого полоса разрушенного вдоль берега ледяного покрова расширялась за счёт последующих проходов СВП вдоль неё с резонансной скоростью, так как наличие свободной кромки значительно уменьшало несущую способность ледяного покрова. Таким образом, лёд разрушался на большой площади.

Эти факты послужили основанием для более детальных экспериментальных модельных исследований возможностей повышения эффективности РМРЛ за счёт использования подобных условий и вышеописанного маневрирования СВП.

\section{Модельные эксперименты}

Эксперименты проводились под руководством и в созданном автором опытовом бассейне $(\mathrm{L} \times \mathrm{B} \times \mathrm{H}=5,0 \times 1,9 \times 0,7$ м) лаборатории механики сплошных сред Амурского гуманитарно-педагогического государственного университета в 2018 г. в соответствии с разработанной методикой моделирования ИГВ в ледяном покрове и приведенной в работе [5]. Моделирование ледяного покрова осуществлялось с использованием модели неразрушаемого ледяного поля. В качестве модельного материала использовалась листовая резина толщиной 2 мм, удовлетворяющая приемлемым условиям геометрического подобия и физико-механическим характеристикам модельного льда в условиях моделирования, что в бассейне с его указанными выше геометрическими параметрами практически исключало влияние масштабного эффекта на результаты экспериментов. Значения и зависимость модуля упругости резины от скорости ее нагружения определялась путем испытаний образцов материала на растяжение при характерных для резонансных ИГВ режимах на специально изготовленном стенде. Его среднее значение составило 6 МПа, что в соответствии с методикой моделирования обеспечивало проведение модельных экспериментов в масштабе 1:500, т.е. в опытах модели- 
ровался ледяной покров толщиной 1 м. ИГВ возбуждались движущейся за счет буксировочной системы бассейна нагрузкой (моделью) массой 76 г и площадью основания 40 см$^{2}$.

\section{Результаты экспериментальных исследований}

Исследования проводились при различных углах наклона дна $\beta\left(10^{\circ}, 20^{\circ}, 30^{\circ}\right)$ и при глубине акватории $\mathrm{H}=30$ м (после пересчёта на натуру). Наклонность дна и условия экспериментов моделировались по схеме, представленной на рис. 1 (где $\mathrm{S}$ - длина наклонного дна). Для $30^{\circ} \mathrm{S}$ составляла 0,30 м; для $20^{\circ}-0,44$ м; для $10^{\circ}-0,86$ м.
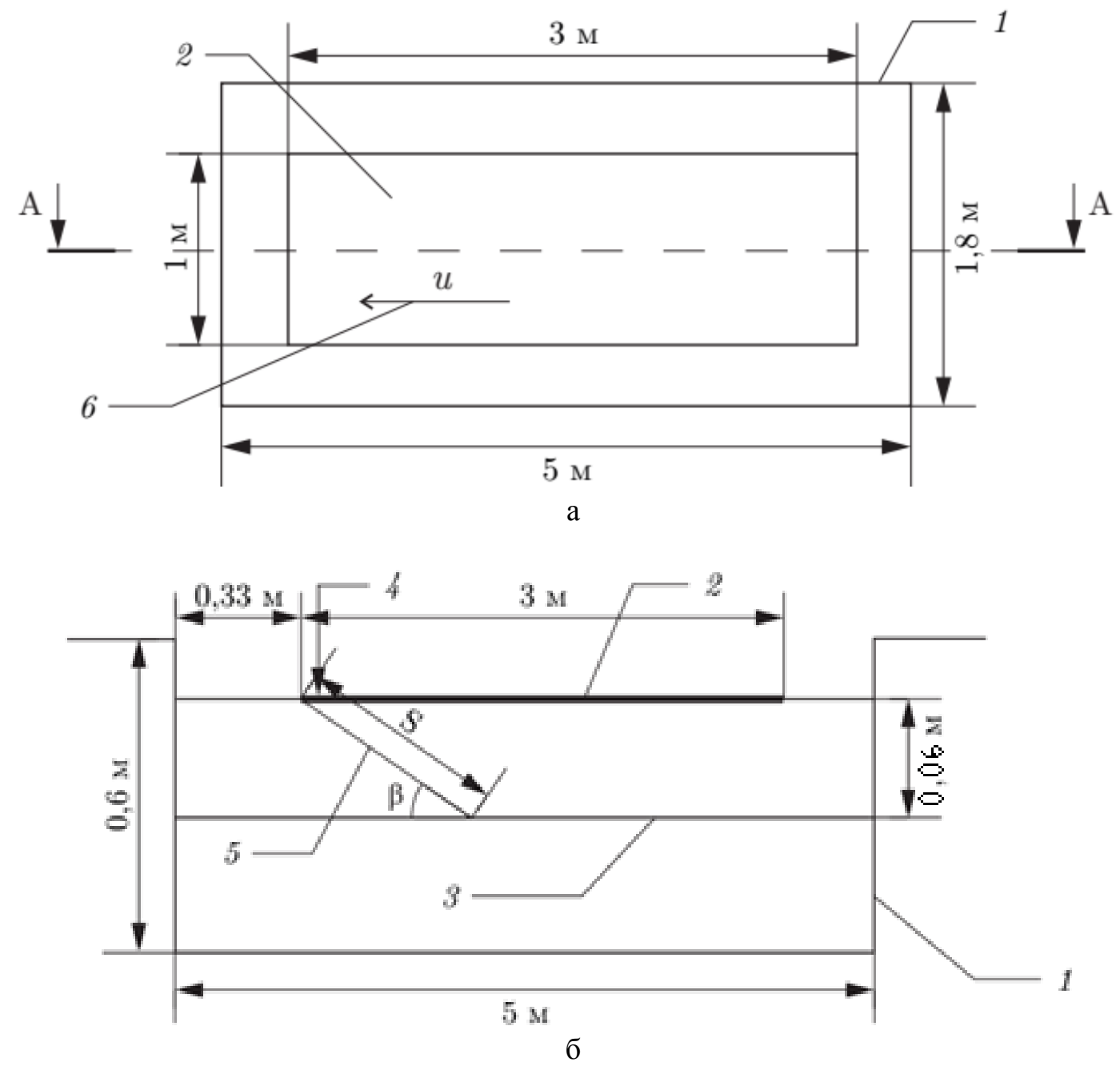

Рис. 1. Схема установки: а - вид сверху, б - сечение по А-А: 1 - чаша бассейна;

2 - модельный лёд; 3 - подвесное дно; 4 - место установки датчика; 5 - наклонное дно; 6 - направление движения нагрузки.

В процессе проведения экспериментов были получены зависимости высоты ИГВ в модельном льду (рис. 2) и относительной выстоты ИГВ $\overline{\mathrm{A}}$ (где $\overline{\mathrm{A}}=\mathrm{A}_{\beta} / \mathrm{A}_{\max } ; \mathrm{A}_{\beta}$ - высота волны при соответствующих $\beta ; \mathrm{A}_{\max }$ - максимальная высота волны без выхода нагрузки на берег) от относительной скорости нагрузки $\chi$ (где $\chi=\mathrm{u} / \sqrt{g} H ; \mathrm{u}-$ скорость нагрузки; $\mathrm{g}-$ ускорение силы тяжести; Н - глубина воды) при различных углах наклона льда (рис. 3). Как иллюстрируют графики, в области низких скоростей наиболее эффективным оказалось движение нагрузки вдоль более крутого берега. С ростом скорости нагрузки амплитуда прогибов ИГВ начинала уменьшаться. К аналогичному результату приводило и уменьшение наклонности дна. 


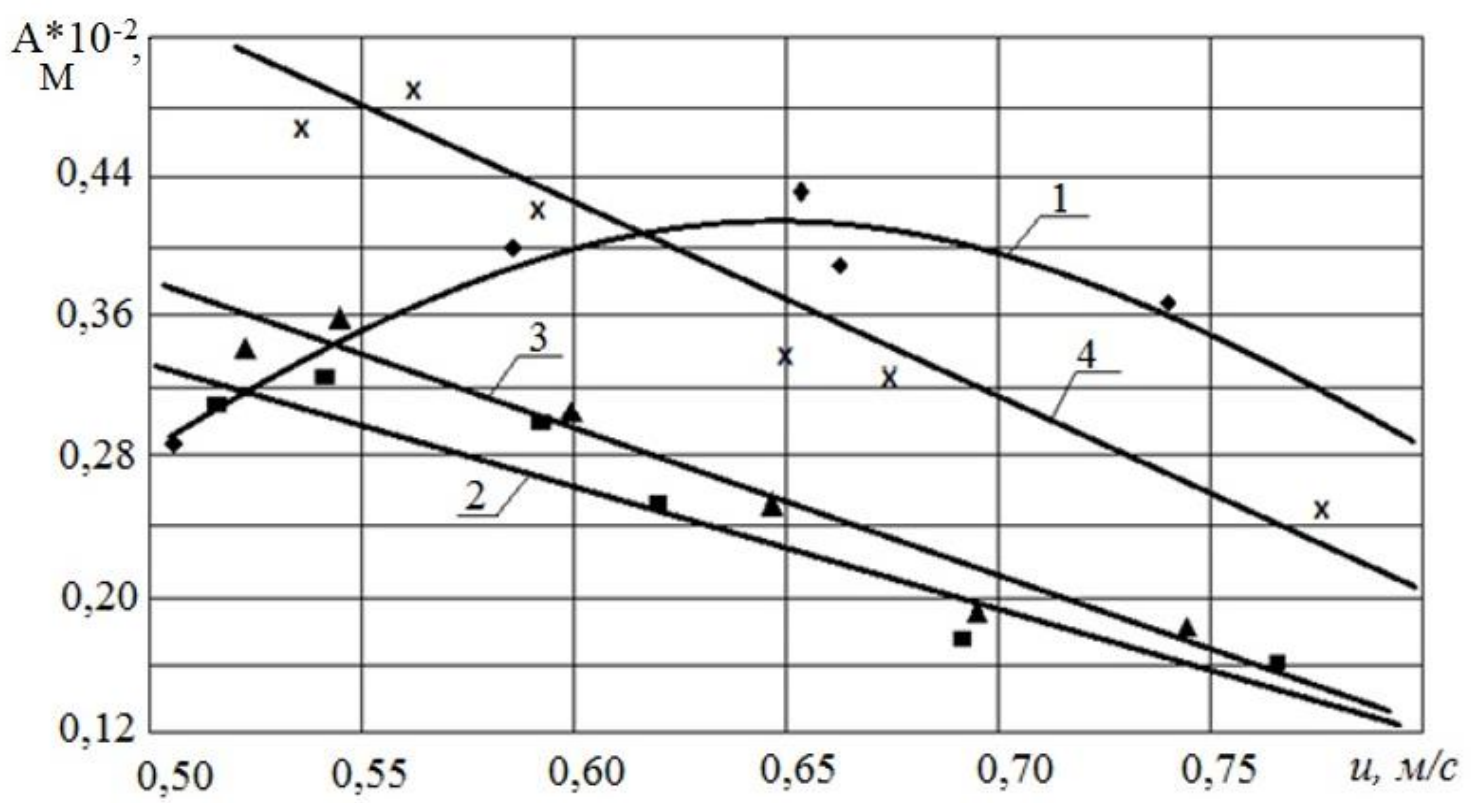

Рис. 2. Зависимость высоты ИГВ в модельном льду от скорости движения нагрузки при различных углах наклона дна (H = 0,06 м), $\beta=20^{\circ} ; 1(\diamond)-$ без выхода на берег; 2 (घ) - $\beta=10^{\circ}$; $3(\Delta)-\beta=20^{\circ} ; 4(x)-\beta=30^{\circ}$.

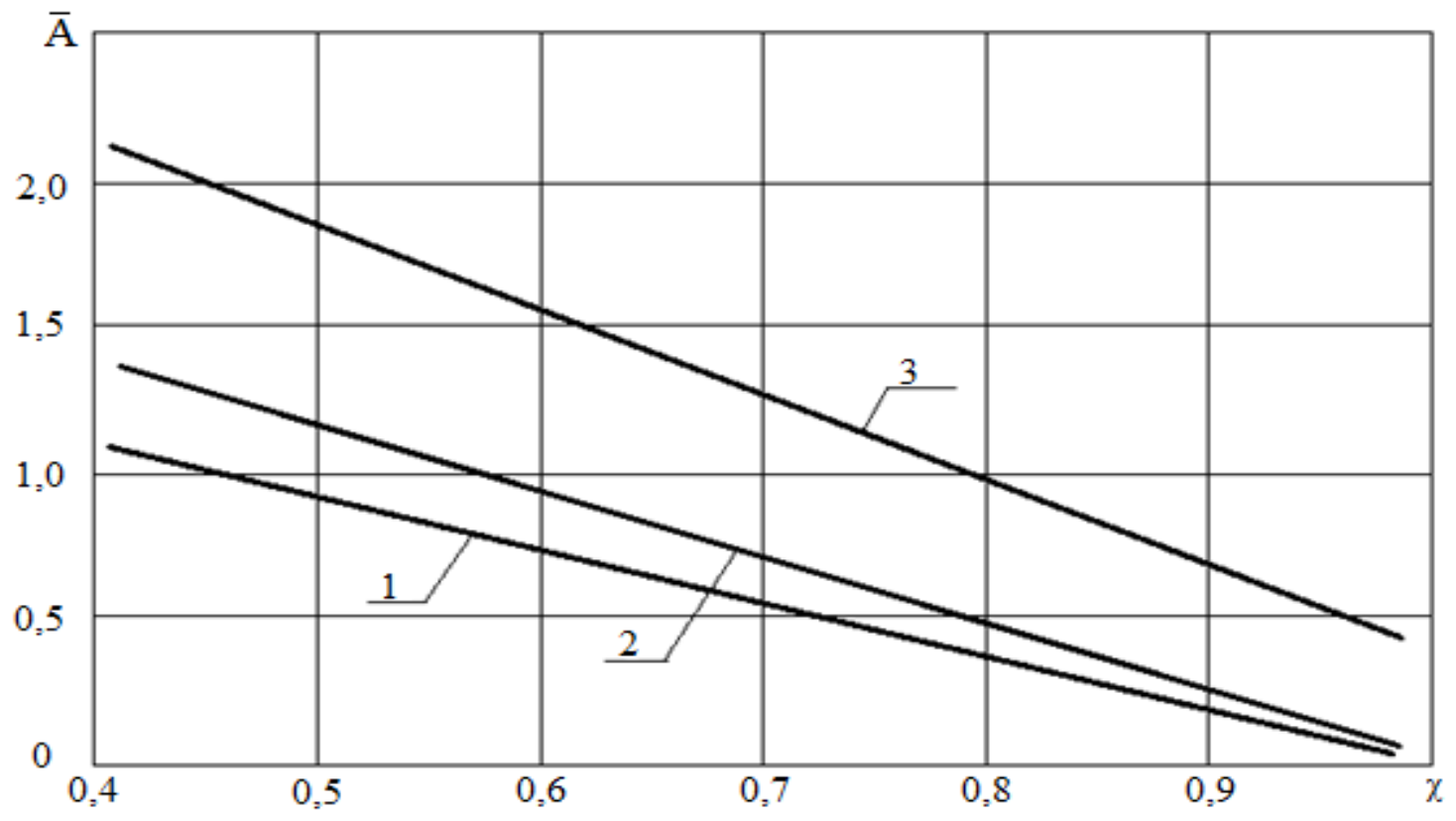

Рис. 3. Зависимость относительной высоты ИГВ от углов наклона дна $\left(1-\beta=10^{\circ} ; 2-\beta=20^{\circ} ; 3-\beta=30^{\circ}\right)$.

Рекомендации для повышения эффективности РМРЛ за счет выхода СВП на берег

Выполненные экспериментальные исследования показали, что для увеличения возможностей РМРЛ (в случаях, когда имеющееся СВП неспособно разрушить ледяной покров заданной толщины при его движении с резонансной скоростью в условиях глубокой воды) следует найти участок акватории с крутым, но одновременно безопасным для выхода СВП со льда берегом. Затем на разных скоростях, близких к резонансным, для средней глубины 
водоема на данном участке, сделать несколько проходов СВП вдоль берега в непосредственной от него близости. Если разрушения кромки льда все же не произойдет, то под прямым углом к береговой линии следует осуществлять выход судна на берег, что, как было указано выше, увеличит ледоразрушающую способность возбуждаемых ИГВ. После разрушения кромки ледяного покрова начинают движение судна вдоль нее с резонансной для соответствующих глубин скоростью. В результате за счет использования такого маневрирования будет разрушен более толстый лед, т.е. повышена эффективность РМРЛ.

Использовать явление увеличения ледоразрушающей способности ИГВ, возбуждаемых СВП при выходе судна на берег, также можно следующим образом. Если параметры судна не позволяют разрушить ледяной покров резонансным методом в данных ледовых условиях, то ожидают время наступления максимального прилива. За счет подъема воды ледяной покров, примерзший к берегу, начнет испытывать наибольшие изгибные деформации у его береговой кромки, т.е. в месте своеобразной жесткой заделки (иногда в морских условиях они являются причиной отрыва берегового припая от берега). Для их использования при разрушении льда резонансными ИГВ СВП при достижении максимального прилива следует перемещать перпендикулярно кромке береговой линии. Первая вершина ИГВ, движущаяся впереди судна и вызывающая изгибные деформации того же знака, что и прилив, увеличит изгибные напряжения во льду у берега, что при достаточных параметрах СВП облегчает процесс разрушения кромки ледяного покрова. При этом, если позволяет рельеф, СВП следует выводить на берег. Если берег крутой, то для предотвращения столкновения с ним СВП перемещают под углом к береговой линии (рис. 1). После возбуждения ИГВ максимальной амплитуды при движении СВП с критической скоростью, которую можно определить разработанными автором способами [5], судно разворачивают или тормозят вблизи берега. Возбужденные же ИГВ, благодаря накопленной кинетической энергии, по инерции будут продолжать распространяться и достигнут береговую линию, что за счет гидроудара позволит с меньшими энергозатратами оторвать ее от берега. Наличие у льда свободной кромки уменьшит его несущую способность. В результате этого последующее движение СВП вдоль этой кромки с резонансной скоростью приведет к возбуждению ИГВ большей амплитуды, что увеличит ледоразрушающую способность судна, т.е. толщину разрушаемого льда (см. пат. 2203826 РФ).

Задача по использованию наклонности дна для повышения ледоразрушающей способности ИГВ может быть решена путем их возбуждения при движении СВП с резонансной скоростью вблизи и вдоль береговой линии во время морского отлива на расстоянии от кромки льда, примерзшего к берегу, равном полудлине волны статического прогиба ледяного покрова [5]. Для этого судну сообщают поперечные перемещения с амплитудой, не превышающей половину длины ее волны, и с частотой резонансных ИГВ. Поперечные перемещения, т.е. движения бортом к берегу и от него и неизбежно сопутствующий этому крен приведут к возбуждению дополнительной системы резонансных ИГВ. Эти волны при приближении к берегу, т.е. при выходе на мелководье с наклонным дном и последующим выходом на берег, будут трансформироваться: длина волны будет уменьшаться, а высота волны увеличиваться. В результате наложение этой волновой системы на систему ИГВ от поступательного движения СВП вдоль береговой линии приведет к увеличению высоты суммарных ИГВ, что увеличит их ледоразрушающую способность. Таким образом, вышеописанное маневрирование СВП повысит его ледоразрушающую способность (см. пат. 2531857 РФ).

\section{Заключение}

Выполненные экспериментальные исследования ледоразрушающих способностей натурных СВП в ледовых условиях, а также их моделей в опытовом бассейне на неразрушаемой (полимерной) модели льда показали возможность существенного увеличения эффективности РМРЛ за счет соответствующего использования близости его береговой линии 
(мелководья и переменности глубины, т.е. наклона дна бассейна). Так, вблизи берега в рассмотренном диапазоне изменения углов наклона дна вблизи деформации, а значит и изгибные напряжения, возрастали более чем в два раза. Это подтверждает перспективность и практическую значимость полученных результатов, а также указывает на целесообразность дальнейших, более детальных, исследований в этом направлении. Кроме того, приведены разработанные автором приемы маневрирования СВП вблизи кромки льда, увеличивающие его разрушаемую толщину. Предложенные способы разрушения ледяного покрова могут быть использованы при решении перечисленных в работе ледотехнических задач.

\section{СПИСОК ЛИТЕРАТУРЫ}

1. Богульский И.О. Моделирование контакта толстого упругого слоя на основании винклеровского типа переменного уровня с вертикальной стенкой // Вестник КрасГАУ. 2018. № 4. C. $109-115$.

2. Букатов А.Е. Волны в море с плавающим ледяным покровом. Севастополь: МГИ, 2017. 360 с.

3. Завьялова К.Н., Шишмарев К.А. Об одной задаче движения внешней нагрузки по вязкому битому льду в канале. Известия АлТГУ. Математика и механика. 2019. № 4(108). С. 76-84.

4. Завьялова К.Н., Шишмарев К.А., Хабахпашева Т.И. Движение внешней нагрузки по битому льду в канале. Известия АлТГУ. Математика и механика. 2018. № 4(102). С. 73-78.

5. Козин В.М., Земляк В.Л. Физические основы разрушения ледяного покрова резонансным методом. Комсомольск-на Амуре: ИМиМ ДВО РАН; ПГУ им. Шолом-Алейхема; АмГПГУ, 2013, $250 \mathrm{c}$.

6. Коробкин А.А., Хабахпашева Т.И. Построение точных решений в задаче о плавающей пластине // Прикл. математика и механика. 2007. Т. 71, вып. 2. С. 321-328.

7. Ли Лян, Шхинек К.Н. Предельная несущая способность ледяных балок // Инженерностроительный журнал. 2013. № 1(36). С. 65-74.

8. Марченко А.В., Чумаков М.М. Исследование затухания поверхностных гравитационных волн в прикромочной зоне дрейфующего льда Баренцева моря // Вести газовой науки. 2017. № 4(32). С. 94-103.

9. Погорелова А.В. Плоская задача о воздействии нескольких ударных импульсов на вязкоупругую пластину, плавающую на поверхности жидкости // ПМТФ. 2010. Т. 51, № 2. С. 155-163.

10. Распространение поверхностных волн в ледовых условиях / Букатов А.Е., Букатов А.А., Жарков В.В., Завьялов Д.Д. Севастополь: МГИ, 2019. 204 с.

11. Стурова И.В. Дифракция поверхностных волн на упругой плавающей на мелководье платформе // Прикл. математика и механика. 2001. Т. 65, № 1. С. 114-122.

12. Стурова И.В. Нестационарное поведение плавающей на мелководье балки под действием внешней нагрузки // ПМТФ. 2002. Т. 43, № 3. С. 88-98.

13. Ткачева Л.А. Воздействие периодической нагрузки на плавающую пластину // Изв. РАН. Механика жидкости и газа. 2005. № 2. С. 132-146.

14. Ткачева Л.А. Колебания ледяного покрова с трещиной при воздействии периодической по времени нагрузки // Изв. Рос. акад. наук. Механика жидкости и газа. 2017. № 2. С. 54-64.

15. Ткачева Л.А. Поведение полубесконечного ледяного покрова при равномерном движении нагрузки // Прикладная механика и техническая физика. 2018. Т. 59, № 2. С. 82-98.

16. Korobkin A., Khabakhpasheva T., Papin A. Waves Propagating Along a Channel with Ice Cover. European J. of Mechanics - B/Fluids. 2014;47:66-175.

17. Wang K., Hosking R., Milinazzo F. Time-dependent response of a floating viscoelastic plate to an impulsively started moving load. J. Fluid Mech. 2004;521:295-317. 
FEFU: SCHOOL of ENGINEERING BULLETIN. 2020. N 3/44

Theory of the Ship and Construction Mechanics

www.dvfu.ru/en/vestnikis

DOI: http://www.dx.doi.org/10.24866/2227-6858/2020-3-4

Kozin V.

VICTOR KOZIN, Doctor of Engineering Sciences, Professor, Institute of Machine Science and

Metallurgy, FEB RAS, ORCID: https://orcid.org/0000-0002-2673-469X,

ResearcherID: S-6053-2016, ScopusID: 8548383800, e-mail: kozinvictor@rambler.ru

Khabarovsk Federal Research Center FEB RAS

Komsomolsk-on-Amur, Russia

\title{
The increase of the ice-breaking ability of flexural-gravitational waves as they approach the shore
}

\begin{abstract}
The paper considers the possibility of increasing the efficiency of the resonance method of ice cover destruction (RRL), i.e. by exciting resonant bending-gravitational waves (IGW) of an amphibious hovercraft (SVP) in solving such important economic problems as: clearance of ice complications in the form of congestion and blocking on rivers flowing from south to north; extension of navigation on inland waterways; early opening of ice reservoirs on the lower tail of hydroelectric power stations in order to increase their power generation, etc. through the use of appropriate maneuvering of vessels near the shore. Due to the complexity of the process of ice cover destruction due to the influence of the proximity of the coast on it, only general information on the destruction of ice from full-scale SVPs in the field and the results of studies carried out in an experimental pool on elastic films simulating ice cover are presented. As a result of research, deformation of the ice cover during the subsequent movement of vessels along the formed free edge, and hence the bending stresses in the ice, increased significantly. The paper presents the results of experimental studies of the dependence of the height of the IGW, excited in the ice cover by a moving load, when it comes ashore from the angle of inclination of the bottom of the pool. The recommendations on the use of the bottom angle to increase the efficiency of the destruction of the ice cover (increase the thickness of the destroyed ice) by the resonance method are also given.
\end{abstract}

Keywords: ice cover, flexural-gravitational waves, wave height, hovercraft, destruction, resonance method, bottom tilt, modeling.

\section{REFERENCES}

1. Bogulsky I.O. Modeling of contact of a thick elastic layer on the basis of a Winkler type of variable level with a vertical wall. Vestnik KrasGAU. 2018(4):109-115.

2. Bukatov A.E. Waves in the sea with floating ice cover. Sebastopol, Institute MGI, 2017, 360 p.

3. Zavyalova K.N., Shishmarev K.A. On a problem of external load movement on viscous broken ice in a channel. Izvestia ASU. Mathematics and Mechanics. 2019(108):76-84.

4. Zavyalova K.N., Shishmarev K.A., Khabakhpasheva T.I. Movement of external load on broken ice in the channel. Izvestia ASU. Mathematics and Mechanics. 2018(102):73-78.

5. Kozin V.M., Zemljak V.L. Physical basis of destruction of ice cover resonance method. Komsomolsk-on-Amur: Institute of Machine Science and Metallurgy, FEB RAS, PSU, Sholom-Aleichem, Amur State University of Humanities and Education. 2013, 250 p.

6. Korobkin A.A., Khabakhpasheva T.I. Construction of exact solutions in the floating plate problem. Applied Mathematics and Mechanics. 2007;71(2):321-328.

7. Li Liang, Shhinek K.N. Ultimate bearing capacity of ice beams. Engineering and Construction J. 2013(36):65-74.

8. Marchenko A.V., Chumakov M.M. Investigation of the damping of surface gravity waves in the marginal ice zone of drifting ice of the Barents sea. Lead Gas Science. 2017(32):94-103.

9. Pogorelova A.V. Flat problem on the effect of several shock pulses on a viscoelastic plate floating on the surface of a liquid. PMTF. 2010;51(2):155-163. 
10. Distribution of surface waves in ice conditions. Bukatov A.E., Bukatov A.A., Zharkov V.V., Zavyalov D.D. Sevastopol, MGI, 2019, 204 p.

11. Sturova I.V. Diffraction of surface waves on an elastic platform floating in shallow water. Applied Mathematics and Mechanics. 2001;65(1):114-122.

12. Sturova I.V. Non-Stationary behavior of a beam floating in shallow water under the influence of an external load. PMTF. 2002;43(3):88-98.

13. Tkacheva L.A. Influence of periodic loading on a floating plate. Izv. RAS. Fluid and Gas Mechanics. 2005(2):132-146.

14. Tkacheva L.A. Fluctuations of the ice cover with a crack under the influence of a periodic time load. Izv. RAS. Fluid and Gas Mechanics. 2017(2):54-64.

15. Tkacheva L.A. Behavior of a semi-infinite ice cover with uniform movement of the load. Applied Mechanics and Technical Physics. 2018;59(2):82-98.

16. Korobkin A., Khabakhpasheva T., Papin A. Waves Propagating Along a Channel with Ice Cover. European J. of Mechanics - B/Fluids. 2014;47:66-175.

17. Wang, K., Hosking, R., F. Milinazzo, Time-dependent response of a floating viscoelastic plate to an impulsively started moving load. J. Fluid Mech. 2004;521:295-317. 